University of Texas at El Paso

DigitalCommons@UTEP

$6-2013$

\title{
Examining Nervios Among Immigrant Male Farmworkers in the MICASA Study: Sociodemographics, Housing Conditions and Psychosocial Factors
}

\author{
Maria Stoecklin-Marois \\ University of California at Davis, mtstoecklin@phs.ucdavis.edu \\ Marc Schenker \\ UC Davis, mbschenker@ucdavis.edu \\ Kathleen A. O'Connor \\ University of Texas at El Paso, kaoconnor2@utep.edu
}

Follow this and additional works at: https://digitalcommons.utep.edu/nursing_papers

Part of the Nursing Commons

Comments:

O’Connor, K., Stoecklin-Marois, M. \& Schenker, M.B. J Immigrant Minority Health (2015) 17: 198.

https://doi.org/10.1007/s10903-013-9859-8

\section{Recommended Citation}

Stoecklin-Marois, Maria; Schenker, Marc; and O'Connor, Kathleen A., "Examining Nervios Among Immigrant Male Farmworkers in the MICASA Study: Sociodemographics, Housing Conditions and Psychosocial Factors" (2013). Departmental Papers (Nursing). 40.

https://digitalcommons.utep.edu/nursing_papers/40

This Article is brought to you for free and open access by the School of Nursing at DigitalCommons@UTEP. It has been accepted for inclusion in Departmental Papers (Nursing) by an authorized administrator of DigitalCommons@UTEP. For more information, please contact lweber@utep.edu. 
Examining Nervios Among Immigrant Male Farmworkers in the MICASA Study: Sociodemographics, Housing Conditions and Psychosocial Factors

\section{Kathleen O'Connor, Maria Stoecklin- Marois \& Marc B. Schenker}

\section{Journal of Immigrant and Minority} Health

ISSN 1557-1912

$\mathrm{J}$ Immigrant Minority Health DOI 10.1007/s10903-013-9859-8

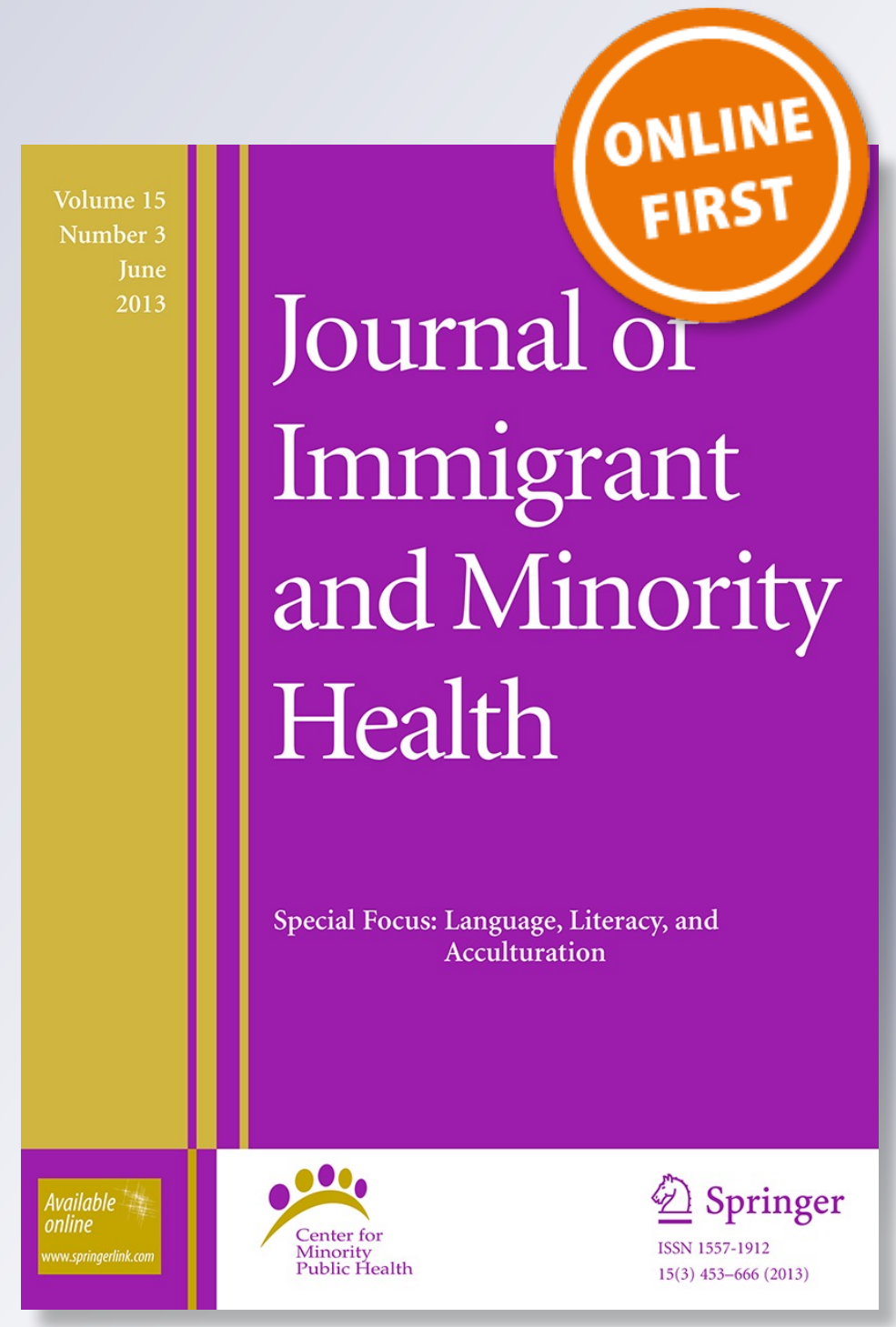

Springer 
Your article is protected by copyright and all rights are held exclusively by Springer Science +Business Media New York. This e-offprint is for personal use only and shall not be selfarchived in electronic repositories. If you wish to self-archive your article, please use the accepted manuscript version for posting on your own website. You may further deposit the accepted manuscript version in any repository, provided it is only made publicly available 12 months after official publication or later and provided acknowledgement is given to the original source of publication and a link is inserted to the published article on Springer's website. The link must be accompanied by the following text: "The final publication is available at link.springer.com". 


\title{
Examining Nervios Among Immigrant Male Farmworkers in the MICASA Study: Sociodemographics, Housing Conditions and Psychosocial Factors
}

\author{
Kathleen O'Connor - Maria Stoecklin-Marois • \\ Marc B. Schenker
}

(C) Springer Science+Business Media New York 2013

\begin{abstract}
Nervios is a culturally defined condition of psychological stress with important implications for Latino health. Using epidemiological research methods, we examined the prevalence of nervios and associated risk factors, including drug and alcohol use, acculturation, and housing conditions in a population-based study of farm worker families in Mendota, CA (the MICASA Study). A household enumeration procedure was used for sampling, and 843 individuals were interviewed in 2006-2007. In this analysis, we present data on 422 men, 381 accompanied (family) males and 41 unaccompanied males. The prevalence of nervios was $22 \%$, with no difference in prevalence by household status. Low family incomes, drug use, medium/high acculturation, and poor housing conditions were associated with increased odds of nervios. Selfreported poor/fair health, depressive symptoms, and high perceived stress were also associated with nervios. Since nervios has been shown to be a clinical indicator of psychiatric vulnerability among Latinos, this analysis furthers public health goals of reducing health disparities.
\end{abstract}

Keywords Farmworkers - Latinos $\cdot$ Mental health · Nervios

\footnotetext{
K. O’Connor ( $₫)$

School of Nursing, The University of Texas at El Paso, CHSN Building, Wiggins Road Room 316, 500 University Avenue, El Paso, TX 79968, USA

e-mail: kaoconnor2@utep.edu

M. Stoecklin-Marois - M. B. Schenker

Department of Public Health Sciences, University of California at Davis, Davis, CA, USA

e-mail: mtstoecklin@phs.ucdavis.edu

M. B. Schenker

e-mail: mbschenker@ucdavis.edu
}

\section{Background}

Nervios is a culturally-defined mental health condition that is shared across Latino subgroups with considerable intergroup agreement as to specific features [1]. The signifier nervios at once connotes the illness nervios, specific symptoms pertaining to nervios, and the illness experience of nervios, as well as a strategy for coping in adverse life conditions [1-3]. Lack of understanding of culture-bound syndromes such as nervios contributes to the creation and perpetuation of health disparities among Latinos. Although sufficient data exists to conclude that mental health is a serious concern for immigrants, there remains a lack of research regarding specific psychosocial challenges faced by Latino immigrant farm workers, a vulnerable and hard-to-reach population.

Latinos in the United States represent a rapidly growing segment of the US population, comprising approximately 50.5 million or $16 \%$ of the US population in the 2010 US Census; however, Latino farm workers are disproportionately overrepresented among agricultural workers [4]. Nationally over 2.6 million people are employed in agricultural labor [5-7]. In California, estimates suggest that over 450,000 people are employed in agriculture, with more than two-thirds being of Latino ethnicity [6].

There are innumerable stressors faced by Latino immigrants that may predispose them to negative mental health outcomes, including nervios. California farm workers and immigrant Latinos face disadvantages in prevention and management of mental health problems because they are among the least assimilated immigrants, despite long US residencies. Compounding the problem are low family incomes and limited access, availability, and utilization of mental health services. Some of the important risk factors are related to individual circumstances of immigration, poverty, and weakened social support, particularly among 
males immigrating without their families [8]. The experience of immigration in general carries significant mental health risk, and creates conditions for increased anxiety and depression [9-11].

Although not considered by Latinos to be a mental illness, which would carry significant stigma, nervios has nevertheless been clinically associated with depression and anxiety. As an idiom of distress, nervios is considered to be clinically useful to identify psychiatric vulnerability among Latinos [12-15]. Lewis-Fernandez et al. [15] describe the symptoms of nervios as anxiety, depression and somatization; having "too many thoughts," irritability, sadness, fearfulness, predisposition to explosive anger, and even psychosis [3, 16, 17]. Other symptoms found to be connected with nervios include hopelessness, nervousness, inability to function in occupational roles; trembling, sweating, feelings of suffocation, loss of control, and desperation; and somatic symptoms including headaches, chest and abdominal pains, and high and low blood pressure $[1,18]$. The syndrome has been reported more frequently among women, and therefore is less well characterized in men [1, 19]. However, it is likely that men may also be affected to a significant degree, and factors associated with nervios among male agricultural workers may represent a unique set of circumstances that warrant closer investigation and analysis.

For example, adverse material life conditions and risk behaviors, such as alcohol use, have been found to increase the prevalence of nervios [20]. Substandard housing and lack of control over living conditions have been implicated as a source of stress for migrant farm workers and increase the risk for negative mental health outcomes, particularly anxiety and depression [21-23]. Magaña and Hovey, in a qualitative study of 75 farm workers in the Midwest, found that crowded living conditions may be associated with nervios [22]. Acculturative stress, the feeling of stress and anxiety resulting from life changes in adapting to the receiving society, and low social support also correlate positively with nervios [24-26].

In addition to these risk factors for nervios, male Latino farmworkers in California are more likely to immigrate without their spouses or families. According to 2003-2004 data from the National Agricultural Worker Survey (NAWS), $60 \%$ of male farmworkers were in California without any members of their immediate family [27]. This group is most vulnerable to substandard housing conditions because of their unaccompanied status [28].

Sensitivity to culturally-interpreted idioms of distress furthers public health goals of reducing health disparities, particularly in minority and immigrant populations that are medically underserved. Understanding the relationships between nervios and Latino farmworker environment and culture is essential to addressing the health risks of this population. These relationships are complicated by Latino use of the term nervios to describe mental health distress, which may be masking more extensive prevalence of depression, anxiety and post-traumatic stress disorder (PTSD) among immigrants who are less likely to report symptoms according to Western diagnostic categories. In this paper, we describe socio-demographic and housing characteristics of a cohort of Latino immigrant farm workers in Fresno County, California, specifically examining two segments of this population-family and unaccompanied males. Additionally, we assess the prevalence of nervios and the possible association with potential risk factors such as housing conditions, alcohol and drug use, acculturation, depressive symptoms, family support, and perceived stress. Our goal is the improved understanding of the prevalence and etiology of this syndrome, which will assist health providers in distinguishing between Western notions of depression and anxiety, which are stigmatized in Hispanic culture, from the more culturally acceptable idiom of distress, nervios. We believe that clients would be more likely to seek care for a familiar, non-stigmatized malaise, furthering the public health goal of reducing health disparities.

\section{Methods}

Participants

The Mexican Immigration to California: Agricultural Safety and Acculturation (MICASA) Study is a prospective cohort study of farm worker families in Mendota, CA. Mendota was chosen as the study site because of the high proportion of farm workers in the population, both permanent residents and seasonal migrant laborers. A two-stage stratified area probability sampling strategy was used with household enumeration to identify and recruit eligible participants. The enumeration procedure was conducted in July 2005 with participant recruitment commencing in December 2005. Further details of the sampling and enumeration procedures have been previously described [29]. Eligible participants were 18-55 years of age, self-identified as Mexican or Central American, resided in Mendota at the time of interview, and lived with at least one household member who had worked in agriculture for 45 days or more in the year prior to the interview. At recruitment, the study objectives and procedures were explained, and written informed consent in Spanish was obtained. All study protocols and procedures were approved by the Institutional Review Board of the University of California, Davis.

\section{Data Collection}

Baseline interviews were completed with participants between January 2006 and April 2007. A questionnaire was 
administered to both the head of household and spouse for all households that agreed to participate, and interviews were conducted in Spanish by trained interviewers hired from the community. Overall, 467 households participated in baseline interviews, resulting in 843 individual interviews ( $81 \%$ participation). One hundred ninety-six individuals declined, and 350 were determined ineligible. The present analysis describes results on 422 men who completed the baseline interview. Of these, 381 men were residing in the US with their family and 41 were termed "unaccompanied" since they were in the US for work, their families remaining in the country of origin.

\section{Measures}

The baseline interview assessed demographic characteristics, smoking, alcohol and drug use, work history, acculturation, housing conditions and psychosocial factors including nervios, depressive symptoms, perceived stress and family support. The questionnaire was conducted in the participant's home or at the project office and required approximately $1 \mathrm{~h}$ to complete. Questions on nervios were based upon the work of Salgado de Snyder et al. [2]. A general question asked if the individual reported ever having nervios. In addition, symptoms of nervios were assessed concurrent with the general question and included whether participants had ever felt distracted or absent-minded; sad, depressed or down; irritable or angry; or having an idea stuck in one's mind. Depressive symptoms were assessed using the Center for Epidemiologic Studies Depression Scale (CES-D) adapted by Burnam et al. [30].

A short six-item Perceived Stress Scale (PSS) with Likert responses was derived from the original 14-item PSS [31]. Higher scores indicated higher levels of perceived stress, and a cutpoint was made at the median. Because the items comprising the scale were adapted from a standardized source, internal reliability was assessed using Cronbach's $\alpha$, which was 0.80 . Family support, a measure of social support, was assessed using a 7-item measure from the family dimension of the provision of social relations (PSR) Scale [32]. In a similar fashion, a cutpoint was made at the median with higher scores indicating higher levels of family support. Internal reliability was evaluated, and Cronbach's $\alpha$ for these items was 0.88 .

Acculturation score was determined using the Acculturation Rating Scale for Mexican Americans-II (ARSMA-II), which assesses language preference, ethnic identity and ethnic interaction [33]. Since there are precedents in the literature for employing the ARSMA-II with non-Mexican Hispanics, the instrument was used with all participants, even though a substantial number of participants were Central American [34-37]. Scores can be classified into five levels of acculturation, however, few participants scored into levels II through $\mathrm{V}$ on the ARSMA-II, so these were collapsed into one medium/high acculturation category.

Questions to examine housing conditions were drawn from previous survey instruments and used indicators that included home ownership; availability of heat in the home; water damage and presence of molds; and presence of cockroaches [38].

\section{Analysis}

Statistical analysis examined the relationships between reported nervios and demographic and behavioral characteristics, housing conditions and psychosocial factors among all males and by household status (unaccompanied vs. family male). $\chi^{2}$ tests were used to compare categorical variables, and $t$ tests were computed to compare continuous variables. Bivariate comparisons between nervios with variables of interest and potential confounders were made for model building determinations. Multivariate logistic regression modeling, with census tract and census block included as strata and cluster variables, was performed to account for potential within-cluster correlation. Crude and adjusted prevalence odds ratios (ORs) and $95 \%$ confidence intervals (CIs) were estimated for nervios by selected behavioral characteristics, acculturation, housing conditions and psychosocial factors. Models were adjusted for age entered as a continuous variable, income, and education. Variables retained in final models were determined by a priori knowledge or those resulting in $10 \%$ change in OR point estimate with inclusion. Data were analyzed with SAS statistical software, version 9.2 for Windows (SAS Institute, Cary, NC, USA).

\section{Results}

Unaccompanied and Family Male Characteristics

Among men, 381 family and 41 unaccompanied men were interviewed. Mean age was 38.5 years $(\mathrm{SD}=10$ years), the majority were from Mexico, and two-thirds had primary school education or less (Table 1). Unaccompanied men were less likely to be married or living as married and were more likely to be current smokers compared to family males (Table 1). Level of acculturation was low overall, with only $5 \%$ of both family and unaccompanied males classified as medium/high acculturated. Unaccompanied males reported lower annual incomes, with $49 \%$ earning $\$ 10,000$ or less in the past year. They also reported significantly shorter residency in the US compared to family males, 12 versus 18 years respectively $(p<0.0001)$ and 
Table 1 Sociodemographic characteristics of family males and unaccompanied males in MICASA farmworker sample, 2007-2008

\begin{tabular}{|c|c|c|}
\hline Characteristics & $\begin{array}{l}\text { Family males } \\
(\mathrm{n}=381) \\
\%(\mathrm{n})\end{array}$ & $\begin{array}{l}\text { Unaccompanied } \\
\text { males }(\mathrm{n}=41) \\
\%(\mathrm{n})\end{array}$ \\
\hline Age $($ mean $\pm \mathrm{SD})$ & $38.6 \pm 10.6$ & $37.7 \pm 11.4$ \\
\hline $\begin{array}{l}\text { Years living in the US } \\
(\text { mean } \pm \text { SD })\end{array}$ & $17.7 \pm 9.9$ & $12.1 \pm 9.2^{\dagger}$ \\
\hline $\begin{array}{l}\text { Years working in agriculture } \\
\quad(\text { mean } \pm \mathrm{SD})\end{array}$ & $16.7 \pm 9.9$ & $11.9 \pm 9.4^{* *}$ \\
\hline \multicolumn{3}{|l|}{ Marital status } \\
\hline Married/living as married & $99.7(380)$ & $50.0(20)^{\dagger}$ \\
\hline Single/divorced/widowed & $0.3(1)$ & $50.0(20)$ \\
\hline \multicolumn{3}{|l|}{ Education } \\
\hline No school & $5.7(20)$ & $12.5(5)$ \\
\hline Primary & $59.1(207)$ & $57.5(23)$ \\
\hline Greater than primary & $35.1(123)$ & $30.0(12)$ \\
\hline \multicolumn{3}{|l|}{ Annual household income } \\
\hline$\$ 0-\$ 10,000$ & $14.6(54)$ & $48.8(20)^{\dagger}$ \\
\hline$\$ 10,000-\$ 20,000$ & $44.9(166)$ & $39.0(16)$ \\
\hline$>\$ 20,000$ & $40.5(150)$ & $12.2(5)$ \\
\hline \multicolumn{3}{|l|}{ Country of birth } \\
\hline US & $3.4(13)$ & $4.9(2)$ \\
\hline Mexico & $65.6(250)$ & $53.7(22)$ \\
\hline Central America & $31.0(118)$ & $41.5(17)$ \\
\hline \multicolumn{3}{|l|}{ Smoking status } \\
\hline Never & $67.9(258)$ & $78.0(32)^{* *}$ \\
\hline Ex-smoker & $17.1(65)$ & 0 \\
\hline Current smoker & $15.0(57)$ & $22.0(9)$ \\
\hline \multicolumn{3}{|c|}{ Alcohol consumption (drinks/week) } \\
\hline$<10$ & $85.9(323)$ & $77.5(31)$ \\
\hline $10+$ & $14.1(53)$ & $22.5(9)$ \\
\hline Ever used drugs & $4.3(16)$ & $4.9(2)$ \\
\hline \multicolumn{3}{|l|}{ Acculturation level } \\
\hline Low & $94.9(355)$ & $94.9(37)$ \\
\hline Medium/high & $5.1(19)$ & $5.1(2)$ \\
\hline Food insecure & $11.6(44)$ & $19.5(8)$ \\
\hline Poor/fair self-reported health & $34.2(130)$ & $27.5(11)$ \\
\hline $\begin{array}{l}\text { Depressive symptoms } \\
\text { (past week) }\end{array}$ & $13.0(45)$ & $5.1(2)^{\mathrm{a}}$ \\
\hline Nervios (lifetime) & $19.5(74)$ & $27.5(11)$ \\
\hline \multicolumn{3}{|l|}{ Nervios symptoms } \\
\hline Idea stuck in head & $21.4(81)$ & $17.1(7)$ \\
\hline Distracted & $34.3(130)$ & $29.3(12)$ \\
\hline Sad & $74.5(283)$ & $87.8(36)$ \\
\hline Irritable & $80.8(307)$ & $97.6(40)^{* *}$ \\
\hline \multicolumn{3}{|l|}{ Reason given for nervios } \\
\hline Family problems & $23.0(17)$ & $63.6(7)$ \\
\hline $\begin{array}{l}\text { Personal/emotional } \\
\text { problems }\end{array}$ & $14.9(11)$ & $9.1(1)$ \\
\hline Illness & $14.9(11)$ & 0 \\
\hline Financial problems & $12.2(9)$ & $9.1(1)$ \\
\hline
\end{tabular}

Table 1 continued

\begin{tabular}{|c|c|c|}
\hline Characteristics & $\begin{array}{l}\text { Family males } \\
(\mathrm{n}=381) \\
\%(\mathrm{n})\end{array}$ & $\begin{array}{l}\text { Unaccompanied } \\
\text { males }(\mathrm{n}=41) \\
\%(\mathrm{n})\end{array}$ \\
\hline Work issues & $9.5(7)$ & 0 \\
\hline Unspecified & 25.7 (19) & $18.2(2)$ \\
\hline $\begin{array}{r}\text { Family support } \\
(\text { mean } \pm \mathrm{SD})\end{array}$ & $14.2 \pm 0.19$ & $9.9 \pm 0.60^{\dagger}$ \\
\hline Score $\geq 14^{\mathrm{b}}$ & $54.1(192)$ & $16.2(6)$ \\
\hline $\begin{array}{l}\text { Perceived stress score } \\
\quad(\text { mean } \pm \mathrm{SD})\end{array}$ & $4.2 \pm 0.17$ & $4.7 \pm 0.53$ \\
\hline Score $\geq 4^{\mathrm{b}}$ & $55.3(208)$ & $65.0(26)$ \\
\hline \multicolumn{3}{|c|}{$\begin{array}{l}* p<0.05 ; * * p<0.01 ;{ }^{\dagger} p<0.001 \text { for differences between family and } \\
\text { unaccompanied males }\end{array}$} \\
\hline $\begin{array}{l}\text { a' Fisher's exact test } \\
\text { b Scores for family }\end{array}$ & ceived stre & \\
\hline
\end{tabular}

had fewer years of experience working in agriculture $(p=0.0004)$ (Table 1).

The prevalence of nervios was $20 \%$ for family males and slightly higher at $28 \%$ for unaccompanied males, but this difference was not statistically significant (Table 1). Reasons for nervios reported by respondents included family problems $(28 \%)$, personal/emotional problems $(14 \%)$, illness (13\%), and financial problems (12\%). Sixty-four percent of unaccompanied males reporting nervios attributed their nervios to family problems, and for family males, family problems were also the most frequently reported reason $(23 \%)$ (Table 1$)$. There was no statistically significant difference in the prevalence of depressive symptoms or mean perceived stress scores between unaccompanied males and family males although unaccompanied males reported significantly less family support than family males $(p<0.0001)$.

\section{Housing Conditions}

A number of characteristics related to housing were assessed at interview, and many of these items varied significantly by household status. Unaccompanied males were less likely to own a home (15 vs. $58 \%$ ), more likely have lived 1 year or less at the current residence (46 vs. $26 \%$ ) and more likely to report no heat in the residence ( 28 vs. $0.5 \%$ ) (Table 2). There were no differences between family and unaccompanied male homes with respect to reported prevalence of water leaks, water stains and mold in the kitchen or bathroom. However, $39 \%$ of unaccompanied males reported cockroaches inside the home compared to $24 \%$ of family males $(p=0.04)$. Finally, a measure of home disrepair was created to assess overall home conditions, and $44 \%$ of unaccompanied males 
Table 2 Descriptive comparisons of housing conditions, MICASA Study family versus unaccompanied males, 2007-2008

\begin{tabular}{lll}
\hline Characteristics & $\begin{array}{l}\text { Family males } \\
(\mathrm{n}=381)\end{array}$ & $\begin{array}{l}\text { Unaccompanied } \\
\text { males }(\mathrm{n}=41)\end{array}$ \\
\hline Own home & $58.3(109)$ & $15.4(2)^{* *}$ \\
Years in current residence & & \\
1 year or less & $26.0(99)$ & $46.3(19)^{*}$ \\
2-3 years & $29.7(113)$ & $24.4(10)$ \\
4-6 years & $19.7(75)$ & $12.2(5)$ \\
$7+$ years & $24.7(94)$ & $17.1(7)$ \\
Distance between home and farm & \\
$<100$ m & $28.1(102)$ & $12.8(5)^{* *}$ \\
100-500 m & $16.0(58)$ & $5.1(2)$ \\
$>500$ m & $55.9(203)$ & $82.1(32)$ \\
No heat in home & $0.5(2)$ & $27.5(11)^{\dagger}$ \\
Water leaks in home & $7.4(28)$ & $2.4(1)$ \\
Water stains on walls/ceiling & $7.4(28)$ & $7.5(3)$ \\
Mold in kitchen & $3.4(13)$ & $7.3(3)^{\mathrm{a}}$ \\
Mold in bathroom & $8.2(31)$ & $9.8(4)^{\mathrm{a}}$ \\
Use bathroom fan & $73.9(255)$ & $36.8(14)^{\dagger}$ \\
Roaches in home & $24.1(91)$ & $39.0(16)^{*}$ \\
Home disrepair score ${ }^{\mathrm{b}}$ & & $22.0(9)^{\dagger}$ \\
0 & $56.2(214)$ & $34.2(14)$ \\
1 & $26.8(102)$ & $43.9(18)$ \\
$2+$ & $17.1(65)$ & \\
\hline
\end{tabular}

* $p<0.05 ; * * p<0.01 ;{ }^{\dagger} p<0.001$ for differences between family and unaccompanied males

${ }^{\text {a }}$ Fisher's Exact test

${ }^{b}$ Home disrepair score includes seven items: no heat, water leaks, water stains, kitchen mold, bathroom mold, do not use bathroom fan, cockroaches in home

reported two or more items of disrepair in the home compared to $17 \%$ of family males $(p<0.0001)$.

\section{Risk Factors Associated with Nervios}

In unadjusted logistic models, household status (unaccompanied vs. family males) was not associated with nervios (Table 3). Likewise, there were no associations with marital status, education or country of birth. Men earning $<\$ 10,000$ annual income had more than twice the odds of nervios compared to men earning more (Table 3). The odds of nervios were higher among those who reported ever using drugs $(\mathrm{OR}=3.29,95 \%$ CI $1.42-7.67)$, were classified as medium/high acculturated $(\mathrm{OR}=2.85,95 \%$ CI 1.05-6.26), and self-reported poor or fair health $(\mathrm{OR}=2.55,95 \%$ CI 1.66-3.93) (Table 3). The odds of nervios were more than seven times higher in those reporting depressive symptoms and significantly higher in men reporting higher levels of perceived stress (Table 3).
Poor housing conditions, including water leaks in the home, mold in kitchen and bathroom, and cockroaches in the home were all associated with increased odds of nervios among men (Table 3). Additionally, those reporting two or more items on the home disrepair score had more than twice the odds of nervios (Table 3).

Logistic models including census tract and block as cluster and strata variables and adjusted for age, education and income produced findings largely consistent with unadjusted models. Men who had ever used drugs $(\mathrm{OR}=3.47,95 \% \mathrm{CI}$ 1.45-8.28) or were classified as medium/high acculturated $(\mathrm{OR}=3.13,95 \%$ CI 1.25-7.81) reported significantly higher odds of nervios (Table 3). Similarly, in adjusted models, the odds of nervios among men was associated with psychosocial factors including self-rated fair or poor health $(\mathrm{OR}=2.32,95 \%$ CI 1.48-3.65), depressive symptoms $(\mathrm{OR}=7.15,95 \%$ CI 3.41-15.01) and higher perceived stress score $(\mathrm{OR}=1.80,95 \%$ CI 1.03-3.13) (Table 3). Likewise, housing conditions associated with higher odds of nervios in unadjusted models remained significantly associated with nervios in adjusted models although having cockroaches in the home and the home disrepair score were only marginally significant $(\mathrm{OR}=1.61,95 \% \mathrm{CI} 0.97-2.66$ and $\mathrm{OR}=1.89,95 \%$ CI 0.93-3.82, respectively).

\section{Discussion}

Nervios and associated symptoms of depression and anxiety, and by extension, general mental health concerns, are pervasive in this population of male farmworkers in California. Participants who reported depression and stress were more likely to also report nervios, suggesting that nervios might signal negative mental health outcomes, something to which health professionals working with this population should be attuned. Key findings include the strong association of income, drug use, poor self-rated physical and/or mental health and poor housing conditions with this culturallyrelevant mental health condition.

Latino immigrants face significant mental health risks, particularly related to anxiety and depression, both clinically associated with nervios and with similar etiological stressors. These risks may be exacerbated by occupational health risks, poor housing conditions, social isolation and discrimination. Farm labor is dangerous, difficult, and dirty, and workers often have little control over employment conditions making it difficult to take time off for illness, doctor visits or to care for a sick child. Low pay leaves many earning at the US federal poverty level, and immigration to the US for work creates social isolation from family. That rates of Western mental health categories such as depression and anxiety are so high among this 
population should come as no surprise, and in fact these prevalence rates are likely significantly underestimated.

The experience of suffering from nervios has previously been correlated with depression and depressive symptoms [1, 3, 17, 23, 39], and in fact, MICASA Study participants with depressive symptoms were seven times as likely to report suffering from nervios. While differences were not statistically significant, it is interesting to note that prevalence of nervios was higher among unaccompanied males while prevalence of depressive symptoms was higher among family males. Since unaccompanied males in our cohort were comprised of newer immigrants compared to family males, the higher prevalence of reported nervios among unaccompanied males is likely to reflect newcomers' preference for and greater identification with familiar, culturally-relevant explanatory models that more meaningfully convey distress; rather than foreign diagnostic categories that signify the stigmatized social identity of mental illness $[12,19]$. These results suggest that mental health issues among farmworkers have the strong potential of being overlooked by US health providers because of linguistic discrepancies in idioms of distress. Further, mental health outcomes tend to be stigmatized among Hispanics, which impedes health-seeking behavior, a factor in the development of and increase in minority health disparities. The culturally-defined illness category of nervios allows individuals to express distress without that stigma.

The $20 \%$ prevalence of nervios reported by MICASA male participants is consistent with estimates on depression reported elsewhere, and our analysis suggests an association between the likelihood of reporting nervios among participants who reported depressive symptoms. Research suggests that between 20 and $50 \%$ of farmworkers in the United States suffer from some type of mental illness or psychiatric vulnerability, although these data often exclude culturally-interpreted idioms of distress such as nervios [39]. In the US-Mexico border region and in agricultural regions of Texas, prevalence rates of nervios are more than double those found in California, 41 and $46 \%$, respectively [40]. In the Midwest, Hovey and Magaña report that $29 \%$ of farm workers suffer from levels of anxiety sufficient to impair daily activity, and $38 \%$ met caseness for depression [21, 41]. Additionally, we found a clear connection between self-reported poor health, high perceived stress and elevated odds of nervios, a finding that agrees with previous research on Latinos who suffered comorbid mental health sequelae such as depression and PTSD from political violence [42].

The nature of the sample afforded the opportunity to examine differences between family male and unaccompanied male immigrant farmworkers, and while the prevalence of nervios by household status was not statistically different, more than a quarter of unaccompanied males reported suffering from this condition compared to $<20 \%$ of family males. Additionally, these two groups of men differed significantly in several key ways indicative of the lifestyles inherent to working unaccompanied in the US compared to migrating and residing with family. Unaccompanied males were less likely to be married; reported significantly lower levels of family support; and were more likely to be smokers than family males. Housing conditions for unaccompanied males tended to be poorer than those of family males, consistent across several items of housing assessment as well as measured as an index of home disrepair. Unaccompanied males represent the newest immigrants (12 years in the US vs. 18 years for family males) and concurrently have a shorter agricultural work history compared to family males, 12 and 17 years, respectively. The lower incomes reported by unaccompanied males, as well as the potential for harsher working conditions, may be related to their recent immigrant status and a contributing factor in the higher prevalence of reported nervios. Stress over money, making ends meet, and sending remittances home likely contribute to increased nervios among men who earn $\$ 10,000$ or less.

The etiology of nervios has long been associated in Latino cultures with family disruption and the breakdown in family relationships, and serves as a means of diverting the expression of stressors associated with familial dysfunction (including separation) into a self-directed idiom of distress [43]. The inability to properly support family or administer family problems likely contributes to the sense among men that family issues are a key reason reported for their nervios. Sixty-four percent of unaccompanied males, compared to only $23 \%$ of family males, cited "family problems" as the main reason for their nervios, a compelling observation given the lower levels of family support reported by the unaccompanied group. For this group, distance from family may be the single most significant factor resulting in limited family communication and interactions, the loss of intimacy with spouse and children, inability to resolve family problems from a distance; and limitations on visits home due to cost and document status.

\section{New Contribution to Literature}

We present new data on nervios among Mexican and Central American male farmworkers, a population for whom there is a significant lack of information. In particular, there is a lack of information about this population with regard to mental health and associations between mental health and the health risks of the immigrant farm worker experience, such as substandard housing and family problems. Because of the associations between depression and nervios found in our analysis, this research provides a 
Table 3 Factors associated with nervios among men in the MICASA Study cohort, 2007-2008

\begin{tabular}{|c|c|c|c|}
\hline Characteristics & Nervios \% (n) & $\begin{array}{l}\text { Unadjusted odds } \\
\text { ratio }[95 \% \mathrm{CI}]\end{array}$ & $\begin{array}{l}\text { Adjusted odds } \\
\text { ratio }^{a}[95 \% \mathrm{CI}]\end{array}$ \\
\hline \multicolumn{4}{|l|}{ Age } \\
\hline $18-30$ years & $20.8(22)$ & $1.00[0.98,1.03]$ & \\
\hline $31-40$ years & $17.0(24)$ & & \\
\hline $41-45$ years & $21.0(13)$ & & \\
\hline $45+$ years & $23.6(26)$ & & \\
\hline \multicolumn{4}{|l|}{ Marital status } \\
\hline Married/living as married & $19.6(78)$ & $0.45[0.18,1.13]$ & \\
\hline Single/divorced/widowed & $35.0(7)$ & 1.0 & \\
\hline \multicolumn{4}{|l|}{ Education } \\
\hline Primary education or less & $19.4(49)$ & 1.0 & \\
\hline Greater than primary & $23.1(31)$ & $0.80[0.46,1.37]$ & \\
\hline \multicolumn{4}{|l|}{ Annual household income } \\
\hline$\$ 0-\$ 10,000$ & $31.5(23)$ & $2.28[1.22,4.28]$ & \\
\hline$\$ 10,000-\$ 20,000$ & $17.8(32)$ & $1.07[0.62,1.86]$ & \\
\hline$>\$ 20,000$ & $16.8(26)$ & 1.0 & \\
\hline \multicolumn{4}{|l|}{ Country of birth } \\
\hline US & $21.4(3)$ & 1.0 & \\
\hline Mexico & $21.1(57)$ & $0.98[0.21,4.54]$ & \\
\hline Central America & $18.5(25)$ & $0.83[0.21,3.35]$ & \\
\hline \multicolumn{4}{|l|}{ Years living in the $\mathrm{US}^{\mathrm{b}}$} \\
\hline$<16$ years & $20.8(43)$ & 1.0 & \\
\hline $16+$ years & $20.0(42)$ & $0.95[0.58,1.58]$ & \\
\hline \multicolumn{4}{|l|}{ Years working in agriculture ${ }^{\mathrm{b}}$} \\
\hline$<15$ years & $19.3(39)$ & 1.0 & \\
\hline $15+$ years & $20.4(43)$ & $1.07[0.72,1.59]$ & \\
\hline \multicolumn{4}{|l|}{ Smoking status } \\
\hline Never & $19.5(56)$ & 1.0 & \\
\hline Ex-smoker & $18.5(12)$ & $0.93[0.52,1.68]$ & \\
\hline Current smoker & $25.8(17)$ & $1.43[0.83,2.47]$ & \\
\hline \multicolumn{4}{|l|}{ Household status } \\
\hline Unaccompanied male & $27.5(11)$ & $1.56[0.54,4.55]$ & $1.32[0.41,4.26]$ \\
\hline Family male & $19.5(74)$ & 1.0 & 1.0 \\
\hline \multicolumn{4}{|c|}{ Alcohol consumption (drinks/week) } \\
\hline$<10$ & $20.8(73)$ & 1.0 & 1.0 \\
\hline $10+$ & $14.5(9)$ & $0.60[0.29,1.27]$ & $0.65[0.32,1.32]$ \\
\hline \multicolumn{4}{|l|}{ Ever used drugs } \\
\hline Yes & $44.4(8) * *$ & $3.29[1.42,7.67]$ & $3.47[1.45,8.28]$ \\
\hline No & $19.5(77)$ & 1.0 & 1.0 \\
\hline \multicolumn{4}{|l|}{ Acculturation level } \\
\hline Low & $19.0(74)^{*}$ & 1.0 & 1.0 \\
\hline Medium/high & $40.0(8)$ & $2.85[1.14,7.10]$ & $3.13[1.25,7.81]$ \\
\hline \multicolumn{4}{|l|}{ Food insecure } \\
\hline Yes & $28.9(15)$ & $1.71[0.77,3.78]$ & $1.56[0.68,3.56]$ \\
\hline No & $19.2(70)$ & 1.0 & 1.0 \\
\hline \multicolumn{4}{|l|}{ Poor/fair self-reported health } \\
\hline Yes & $30.7(43)$ & $2.55[1.66,3.93]$ & $2.32[1.48,3.65]$ \\
\hline No & $14.8(41)$ & 1.0 & 1.0 \\
\hline \multicolumn{4}{|c|}{ Depressive symptoms (past week) } \\
\hline Yes & $53.2(25)^{\dagger}$ & $7.11[3.68,13.75]$ & $7.15[3.41,15.01]$ \\
\hline
\end{tabular}


Table 3 continued

\begin{tabular}{|c|c|c|c|}
\hline Characteristics & Nervios \% (n) & $\begin{array}{l}\text { Unadjusted odds } \\
\text { ratio }[95 \% \mathrm{CI}]\end{array}$ & $\begin{array}{l}\text { Adjusted odds } \\
\text { ratio }^{\mathrm{a}}[95 \% \mathrm{CI}]\end{array}$ \\
\hline No & $13.8(46)$ & 1.0 & 1.0 \\
\hline Family support score $\geq 14^{\mathrm{c}}$ & $24.0(47)$ & $1.53[0.91,2.56]$ & $1.65[0.93,2.95]$ \\
\hline Family support score $<14$ & $17.1(33)$ & 1.0 & 1.0 \\
\hline Perceived stress score $\geq 4^{\mathrm{c}}$ & $23.7(55)^{*}$ & $1.77[0.99,3.15]$ & $1.80[1.03,3.13]$ \\
\hline Perceived stress score $<4$ & $14.9(27)$ & 1.0 & 1.0 \\
\hline \multicolumn{4}{|l|}{ Own home } \\
\hline Yes & $17.4(19)$ & $0.72[0.35,1.47]$ & $0.75[0.32,1.78]$ \\
\hline No & $22.7(20)$ & 1.0 & 1.0 \\
\hline \multicolumn{4}{|c|}{ Distance between home and farm } \\
\hline$<100 \mathrm{~m}$ & $27.1(29)$ & $1.60[0.83,3.09]$ & $1.63[0.82,3.26]$ \\
\hline $100-500 \mathrm{~m}$ & $18.6(11)$ & $0.98[0.51,1.90]$ & $1.18[0.59,2.36]$ \\
\hline$>500 \mathrm{~m}$ & $18.9(44)$ & 1.0 & 1.0 \\
\hline \multicolumn{4}{|l|}{ No heat in home } \\
\hline Yes & $7.7(1)$ & $0.32[0.02,4.34]$ & $0.18[0.01,3.82]$ \\
\hline No & $20.7(84)$ & 1.0 & 1.0 \\
\hline \multicolumn{4}{|l|}{ Water leaks in home } \\
\hline Yes & $48.3(14)^{\dagger}$ & $4.15[1.87,9.21]$ & $4.90[2.11,11.36]$ \\
\hline No & $18.4(71)$ & 1.0 & 1.0 \\
\hline \multicolumn{4}{|l|}{ Water stains on walls/ceiling } \\
\hline Yes & $32.3(10)$ & $2.07[0.97,4.41]$ & $2.00[0.92,4.33]$ \\
\hline No & $18.7(72)$ & 1.0 & 1.0 \\
\hline \multicolumn{4}{|l|}{ Mold in kitchen } \\
\hline Yes & $37.5(6)$ & $2.49[1.11,5.56]$ & $2.40[1.06,5.48]$ \\
\hline No & $19.5(78)$ & 1.0 & 1.0 \\
\hline \multicolumn{4}{|l|}{ Mold in bathroom } \\
\hline Yes & $45.7(16)^{\dagger}$ & $3.90[1.93,7.87]$ & $3.80[1.92,7.53]$ \\
\hline No & $17.8(68)$ & 1.0 & 1.0 \\
\hline \multicolumn{4}{|l|}{ Use bathroom fan } \\
\hline Yes & $20.6(55)$ & $1.09[0.64,1.84]$ & $1.26[0.64,2.48]$ \\
\hline No & $19.3(22)$ & 1.0 & 1.0 \\
\hline \multicolumn{4}{|l|}{ Roaches in home } \\
\hline Yes & $27.1(29)^{*}$ & $1.67[1.05,2.67]$ & $1.61[0.97,2.66]$ \\
\hline No & $18.2(56)$ & 1.0 & 1.0 \\
\hline \multicolumn{4}{|l|}{ Home disrepair score ${ }^{\mathrm{d}}$} \\
\hline 0 & $18.2(40)^{* *}$ & 1.0 & 1.0 \\
\hline 1 & $15.5(18)$ & $0.83[0.45,1.52]$ & $0.91[0.48,1.72]$ \\
\hline $2+$ & $32.5(27)$ & $2.17[1.15,4.09]$ & $1.89[0.93,3.82]$ \\
\hline
\end{tabular}

$* p<0.05 ; * * p<0.01$;

${ }^{\dagger} p<0.001$

${ }^{\text {a }}$ Census tract and block

included as strata and cluster

variables, models adjusted for

age, education, and income

b Years in US and years

working in agriculture divided

at median value

c Scores for family support and perceived stress were divided at the median value for each score

${ }^{\mathrm{d}}$ Home disrepair score includes seven items: no heat, water leaks, water stains, kitchen mold, bathroom mold, do not use bathroom fan, cockroaches in home

nervios among males. The presence of water leaks, mold in

clear indication that health providers should investigate comorbid depression among Latinos who report that they are suffering from nervios.

Our data on housing conditions provides insight into associations with nervios. There is general agreement that housing conditions are implicated in negative mental health outcomes among the poor [22], but no study has definitively linked poor housing conditions to mental health outcomes, partly due to methodological considerations $[39,44]$. In the present analysis, we examined specific features of home disrepair that may increase risks of the bathroom and kitchen, and cockroaches in the home were all individually associated with nervios in men. Additionally, a measure of home disrepair that was a composite score of seven items related to poor housing conditions showed that reporting two or more items of disrepair was associated with higher odds of nervios. Farm workers, especially unaccompanied males, often reside in rental homes that are dismally maintained and regulation of farm worker housing standards remains egregiously neglected. It is understandable that such poor housing 
conditions may contribute to risk of negative mental health outcomes [39].

\section{Limitations}

There are several limitations to this study that should be mentioned inherent to cross-sectional assessments based upon participant interview, such as recall bias and inability to determine temporal order. The questions on nervios and individual symptoms of nervios assessed lifetime nervios, so the time frame of occurrence and whether it preceded immigration to the US was not known. However, since we did find an association between past-week depression and nervios, our data on depression among males suggests at least an indirect association between nervios and housing conditions. Further, our research shows that two or more items of home disrepair in the current home is associated with higher reporting of nervios, also suggestive of an association. Reliance on self-report is vulnerable to recall bias, but assessments used standardized instruments tested with other immigrant populations, where possible. Additionally, the sample of unaccompanied males was small which potentially limited analysis and comparisons that can be drawn with this group. Health research on this important component of the hired farm worker population is inadequate, however, so these descriptive evaluations provide further narrative on the characteristics of this group. A qualitative component that delved further into individual understanding of the etiology of malaise and the cultural meaning of the phenomenon of nervios was beyond the scope of the MICASA Study, but merits further investigation.

\section{Conclusions}

Challenging life conditions and hardships common to the immigrant farmworker experience are positively correlated with an increased prevalence of nervios, which in turn is associated with risk of other mental health issues, including depression. A lack of understanding among health practitioners in the United States regarding Latino attitudes about mental health combined with Latino use of cultural signifiers may mask identifying serious underlying mental health issues. As a result, mental health issues among Latino immigrants present a potential public health crisis that has yet to be well measured.

In conclusion, we have examined specific risk factors that are associated with an increased prevalence of nervios, a culturally-interpreted syndrome that corresponds uneasily to a number of Western diagnostic categories. This analysis builds upon previous research to further understanding of culturally-defined idioms of distress in mental health among Latino immigrants that may be overlooked by health care providers and health policymakers. Since nervios has been shown to be a clinical indicator of other underlying mental health issues, these findings further public health goals of reducing health disparities among vulnerable and hard-to-reach populations by fostering culturally competent understanding of the meaning of idioms of distress, and of the mental health challenges of lowincome immigrant populations.

Acknowledgments This study was funded by grants from the National Institute of Occupational Safety and Health (NIOSH 2U50OH007550 and R01 OH009293) and The California Endowment.

\section{References}

1. Baer RD, Weller SC, de Alba Garcia JG, et al. A cross-cultural approach to the study of the folk illness nervios. Cult Med Psychiatry. 2003;27(3):315-37.

2. de Salgado Snyder VN, Diaz-Perez MJ, Ojeda VD. The prevalence of nervios and associated symptomatology among inhabitants of Mexican rural communities. Cult Med Psychiatry. 2000; 24(4):453-70.

3. Guarnaccia PJ, Lewis-Fernandez R, Marano MR. Toward a Puerto Rican popular nosology: nervios and ataque de nervios. Cult Med Psychiatry. 2003;27(3):339-66.

4. Ennis SR, Ríos-Vargas M, Albert NG. The Hispanic population, US Census Bureau, U.S. Department of Commerce Economics and Statistics Administration; 2011.

5. USDA. 2009 Agricultural Statistics Annual, National Agricultural Statistics Service. Washington, DC: US Government Printing Office; 2009.

6. State of California, California's Agricultural Employment, Employment Development Department; 2008.

7. Kandel W, United States Department of Agriculture, Economic Research Service. Profile of hired farmworkers, a 2008 update. Washington, DC: USDA, Economic Research Service; 2008.

8. Kim-Godwin YS, Bechtel GA. Stress among migrant and seasonal farmworkers in rural southeast North Carolina. J Rural Health Off J Am Rural Health Assoc Natl Rural Health Care Assoc. 2004;20(3):271-8.

9. Familiar I, Borges G, Orozco R, Medina-Mora ME. Mexican migration experiences to the US and risk for anxiety and depressive symptoms. J Affect Disord. 2011;130(1-2):83-91.

10. Grzywacz JG, Alterman T, Muntaner C, et al. Mental health research with Latino farmworkers: a systematic evaluation of the short CES-D. J Immigr Minor Health. 2010;12(5):652-8.

11. Kirchner T, Lara S. Stress and depression symptoms in patients with multiple sclerosis: the mediating role of the loss of social functioning. Acta Neurol Scand. 2011;123(6):407-13.

12. Carpenter-Song E, Chu E, Drake RE, Ritsema M, Smith B, Alverson H. Ethno-cultural variations in the experience and meaning of mental illness and treatment: implications for access and utilization. Transcult Psychiatry. 2010;47(2):224-51.

13. Editorial GuarnacciaP. Methodological advances in cross-cultural study of mental health: setting new standards. Cult Med Psychiatry. 2003;27(3):249-57.

14. Cabassa LJ, Lagomasino IT, Dwight-Johnson M, Hansen MC, Xie B. Measuring Latinos' perceptions of depression: a confirmatory factor analysis of the Illness Perception Questionnaire. Cult Divers Ethnic Minor Psychol. 2008;14(4):377-84. 
15. Lewis-Fernandez R, Hinton DE, Laria AJ, et al. Culture and the anxiety disorders: recommendations for DSM-V. Depress Anxiety. 2010;27(2):212-29.

16. Guarnaccia PJ, Rogler LH. Research on culture-bound syndromes: new directions. Am J Psychiatry. 1999;156(9):1322-7.

17. Lewis-Fernandez R, Gorritz M, Raggio GA, Pelaez C, Chen H, Guarnaccia PJ. Association of trauma-related disorders and dissociation with four idioms of distress among Latino psychiatric outpatients. Cult Med Psychiatry. 2010;34(2):219-43.

18. England M, Mysyk A, Gallegos JA. An examination of nervios among Mexican seasonal farm workers. Nurs Inq. 2007;14(3): 189-201.

19. Jenkins JH. Ethnopsychiatric interpretations of schizophrenic illness: the problem of nervios within Mexican-American families. Cult Med Psychiatry. 1988;12(3):301-29.

20. Cherry DJ, Rost K. Alcohol use, comorbidities, and receptivity to treatment in Hispanic farmworkers in primary care. J Health Care Poor Underserved. 2009;20(4):1095-110.

21. Hovey JD, Magana CG. Exploring the mental health of Mexican migrant farm workers in the Midwest: psychosocial predictors of psychological distress and suggestions for prevention and treatment. J Psychol. 2002;136(5):493-513.

22. Magana CG, Hovey JD. Psychosocial stressors associated with Mexican migrant farmworkers in the Midwest United States. J Immigr Health. 2003;5(2):75-86.

23. Grzywacz JG, Quandt SA, Chen H, et al. Depressive symptoms among Latino farmworkers across the agricultural season: structural and situational influences. Cult Divers Ethnic Minor Psychol. 2010;16(3):335-43.

24. Hovey JD, Magana CG. Psychosocial predictors of anxiety among immigrant Mexican migrant farmworkers: implications for prevention and treatment. Cult Divers Ethnic Minor Psychol. 2002;8(3):274-89.

25. Hovey JD, Magana CG. Cognitive, affective, and physiological expressions of anxiety symptomatology among Mexican migrant farmworkers: predictors and generational differences. Community Ment Health J. 2002;38(3):223-37.

26. Alderete E, Vega WA, Kolody B, Aguilar-Gaxiola S. Lifetime prevalence of and risk factors for psychiatric disorders among Mexican migrant farmworkers in California. Am J Public Health. 2000;90(4):608-14.

27. The California Farm Labor Force. Overview and trends from the national agricultural workers survey. Burlingame: Aguirre International; 2005.

28. López NC, Legato N, editors. Housing for families and unaccompanied migrant farmworkers. Washington, DC: Housing Assistance Council; 1997.

29. Stoecklin-Marois MT, Hennessy-Burt TE, Schenker MB. Engaging a hard-to-reach population in research: sampling and recruitment of hired farm workers in the MICASA study. J Agric Saf Health. 2011;17(4):291-302.
30. Burnam MA, Wells KB, Leake B, Landsverk J. Development of a brief screening instrument for detecting depressive disorders. Med Care. 1988;26(8):775-89.

31. Cohen S, Kamarck T, Mermelstein R. A global measure of perceived stress. J Health Soc Behav. 1983;24(4):385-96.

32. Turner RJ, Frankel BG, Levin DM. Social support: conceptualization, measurement, and implications for mental health. Res Community Ment Health. 1983;3:67-111.

33. Cuellar I, Arnold B, Maldonado R. Acculturation rating-scale for Mexican-Americans II-a revision of the original ARSMA scale. Hisp J Behav Sci. 1995;17(3):275-304.

34. Andrews AR 3rd, Bridges AJ, Gomez D. A multi-study analysis of conceptual and measurement issues related to health research on acculturation in Latinos. J Transcult Nurs. 2013;24(2):134-43.

35. Barrera M Jr, Toobert D, Strycker L, Osuna D. Effects of acculturation on a culturally adapted diabetes intervention for Latinas. Health Psychol. 2012;31(1):51-4.

36. Jimenez DE, Gray HL, Cucciare M, Kumbhani S, GallagherThompson D. Using the Revised Acculturation Rating Scale for Mexican Americans (ARSMA-II) with Older Adults. Hisp Health Care Int. 2010;8(1):14-22.

37. Kasirye OC, Walsh JA, Romano PS, et al. Acculturation and its association with health-risk behaviors in a rural Latina population. Ethn Dis. 2005;15(4):733-9.

38. Zock JP, Jarvis D, Luczynska C, Sunyer J, Burney P. Housing characteristics, reported mold exposure, and asthma in the European community respiratory health survey. J Allergy Clin Immunol. 2002;110(2):285-92.

39. Grzywacz JG. Mental health among farmworkers in the Eastern United States. In: Arcury TA, Quandt SA, editors. Latino farmworkers in the Eastern United States: health, safety and justice. New York: Springer; 2009. p. 240.

40. Weigel MM, Armijos RX, Hall YP, Ramirez Y, Orozco R. The household food insecurity and health outcomes of US-Mexico border migrant and seasonal farmworkers. J Immigr Minor Health. 2007;9(3):157-69.

41. Hovey JD, Magana C. Acculturative stress, anxiety, and depression among Mexican immigrant farmworkers in the Midwest United States. J Immigr Health. 2000;2(3):119-31.

42. Eisenman DP, Gelberg L, Liu HH, Shapiro MF. Mental health and health-related quality of life among adult Latino primary care patients living in the United States with previous exposure to political violence. JAMA. 2003;290(5):627-34.

43. Low SM. The meaning of nervios: a sociocultural analysis of symptom presentation in San Jose, Costa Rica. Cult Med Psychiatry. 1981;5(1):25-47.

44. Evans GW. The built environment and mental health. J Urban Health. 2003;80(4):536-55. 